\title{
Bypass Grafting of Aberrant Circumflex Artery with Anomalous Origin and Course
}

\section{Marios E. Patronis, Sotiris C. Papaspyros*, Kasra Shaikhrezai, Sai Prasad, Dharmendra Agrawal}

Department of Cardiothoracic Surgery, Royal Infirmary of Edinburgh, Edinburgh, Scotland.

Email: *sotirispapaspyros@gmail.com

Received October $11^{\text {th }}, 2012$; revised November $14^{\text {th }}, 2012$; accepted November $21^{\text {st }}, 2012$

\begin{abstract}
We present a case of a rarely seen anomalous circumflex $(\mathrm{Cx})$ artery originating from the proximal right coronary artery. This was an incidental finding during a diagnostic coronary angiogram performed to investigate a patient with acute coronary syndrome. Surgically significant disease was present in four left-sided vessels. The patient underwent coronary artery bypass grafts using left internal thoracic artery and long saphenous vein grafts to all four left sided vessels including the aberrant Cx. We also present a discussion of current relevant literature and guidelines in relation to definition, classification, incidence, diagnosis, clinical relevance and treatment of this type of coronary artery anomalies.
\end{abstract}

Keywords: Coronary Artery Anomalies; Coronary Artery Bypass Grafts

\section{Case Report}

A 64-year-old Caucasian male presented to our hospital with new, sudden onset, chest pain and shortness of breath. Risk factors included smoking, hypertension and hyperlipidaemia. There were no significant co-morbidities and his past medical history was clear. Physical examination was unremarkable.

A provisional diagnosis of acute coronary syndrome led to the following investigations: Electrocardiogram which showed sinus rhythm and T-wave inversion in leads V2-V6, blood tests with Troponin rise of 0.07, normal biochemistry and normal chest radiograph. Transthoracic echocardiography demonstrated basal-inferior hypokinesis, normal mitral and aortic valves and preserved left ventricular (LV) systolic function.

Coronary angiography revealed a right dominant system with normal left main stem. Significant disease was present in the proximal and mid parts of the left anterior descending (LAD), diagonal (Dx) and intermediate (Int) arteries. The circumflex $(\mathrm{Cx})$ artery had aberrant origin from the proximal right coronary (RCA) artery with severe proximal/mid vessel disease (Figure 1). It coursed behind the aorta and pulmonary artery. The obtuse marginal $(\mathrm{OM})$ branch originated from the $\mathrm{Cx}$ and was occluded with retrograde filling (Figure 2). The RCA did not have surgically significant disease. Good LV systolic function was confirmed.

The patient underwent on pump coronary artery bypass

*Corresponding author.

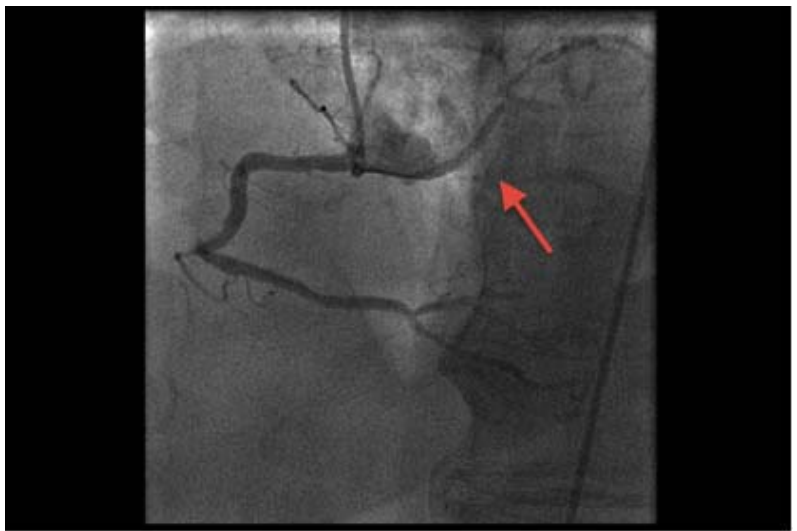

Figure 1. Aberrant, atherosclerotic $\mathrm{Cx}$ originating from RCA.

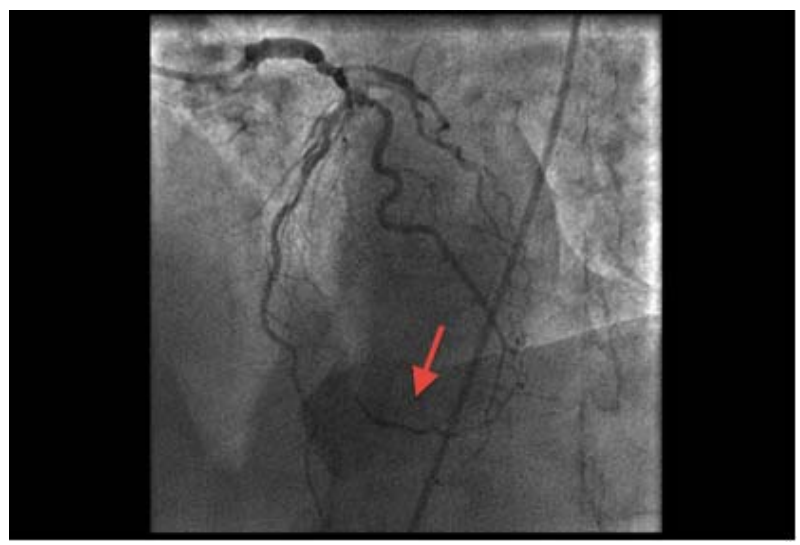

Figure 2. Retrograde filling of OM branch of aberrant $\mathrm{Cx}$. 
grafts (CABG). Left internal thoracic artery was anastomosed to the LAD, long saphenous vein was used for grafts to Dx, Int and OM. Postoperative course was uneventful and the patient was discharged home after eight days.

\section{Discussion}

Coronary artery anomalies (CAA) are a diverse group of congenital disorders with highly variable clinical relevance and pathophysiological mechanisms. No single institution has collected a large enough series to clarify the natural prognosis of each entity. This contributes to ongoing controversy in relation to incidence and clinical identification of these lesions, especially the ones that could lead to angina or sudden cardiac death. Screening and management strategies have caused and are still causing debate among protagonists and antagonists.

\section{Definition}

In an attempt to ascertain consistency in reporting CAAs Angellini et al. (2007) proposed specific criteria to define normal coronary anatomy. The names of coronary arteries are assigned according to their dependent territory, not according to their origin or proximal course.

1) The RCA is the vessel that provides blood flow to the right ventricular free wall. It is not essential for the posterior descending branch to originate from the RCA (the most common pattern) or that the ostium of the RCA be located at the right anterior sinus of Valsalva (which is normal).

2) The LAD is the vessel that provides blood flow to the anterior interventricular septum. It is not essential for the Dx to originate from this vessel (as is normal).

3) The Cx is the vessel that provides blood flow to the free wall of the left ventricle, on the obtuse margin of the heart [1].

\section{Classification}

Seven major categories of coronary artery anomalies have been described [2].

1) Anomalous pulmonary artery origins of the coronaries;

2) Anomalous aortic origins of the coronaries;

3) Congenital atresia of the left main coronary artery;

4) Coronary artery fistulas;

5) Coronary artery bridging;

6) Coronary aneurysms;

7) Coronary stenosis.

\section{Incidence}

Incidence of CAAs ranges from $0.3 \%$ to $5.6 \%$. Most studies are limited by entry biases and a lack of clear diagnostic criteria and they vary from retrospective reviews of diagnostic coronary angiograms, to autopsy series.

In 18,950 autopsies, Alexander and Griffith (1956) observed only 54 coronary anomalies (0.3\%) [3]. Angelini et al. (1999) performed an ad hoc study of 1950 diagnostic consecutive coronary angiograms using specific criteria for CAAs and found a 5.6\% incidence [4]. Other investigators have reported incidences close to 1\% [5-9].

Antopol and Kugel (1933) first described anomalous origin of the Cx from the proximal RCA or right sinus of Valsalva (RSV) [10]. Yamanaka et al. (1990) and Topaz et al. (1992) found that approximately $27 \%$ of coronary anomalies were Cx arising from RCA or RSV. It was the second most common anomaly [5,6]. Wilkins et al. (1988) reported incidence of $45 \%$ in their series (most common coronary anomaly) [7]. Garg et al. (1999) reported incidence of $36 \%$ in their cohort (second most common anomaly) [8].

\section{Diagnosis}

Two angiographic signs have been described to allow recognition of this anomaly.

Aortic root sign: During left ventriculography in a right anterior oblique projection is a profile view of the anomalous $\mathrm{Cx}$ as it courses posteriorly behind the right sinus of Valsalva. The single exception to this observation is in the case where the artery is completely occluded at its origin.

Sign of non-perfused myocardium: During selective opacification of the left coronary artery an avascular area in the posterior lateral left ventricular myocardium suggests anomalous origin of the Cx. Sub-selective injection of the LAD or separate origin of the Cx from the left sinus of Valsalva are easily ruled out by left cusp injections [11].

Figures $\mathbf{3}$ and $\mathbf{4}$ (respectively) demonstrate those signs in our patient's angiogram.

\section{Clinical Relevance}

Coronary anomalies have been implicated in chest pain, sudden death, cardiomyopathy, syncope, dyspnoea, ventricular fibrillation, and myocardial infarction [4].

Anomalous origin of a coronary artery from the opposite sinus (ACAOS) has been recognized as having serious prognostic implications in young individuals [12-14].

A landmark study at the American Armed Forces Institute of Pathology reviewed 6.3 million 18-year-old recruits who underwent intense military training for 8 weeks. Some 64 cardiac deaths occurred. 21 (33\%) were related to ACAOS of the left coronary artery. No other CAAs resulted in cardiac death [15].

In cases of ectopic origination of a CAA, only 1 spe- 


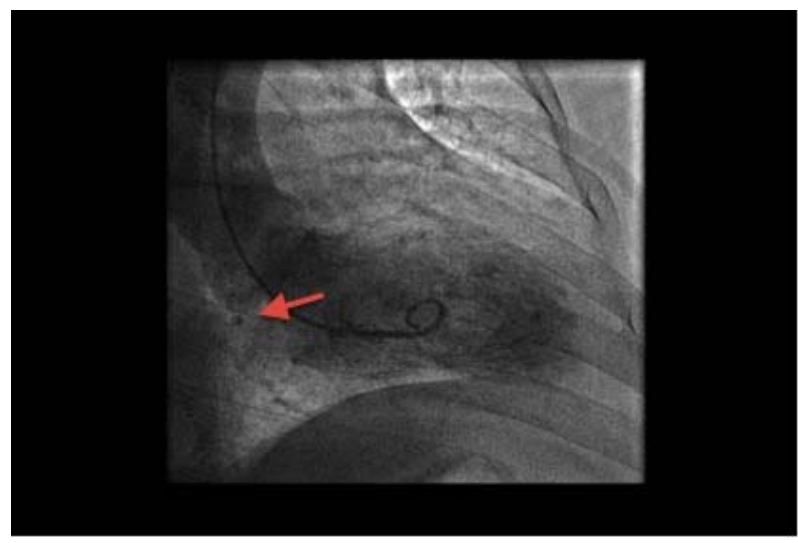

Figure 3. Aortic root sign. Profile view of the aberrant $\mathrm{Cx}$.

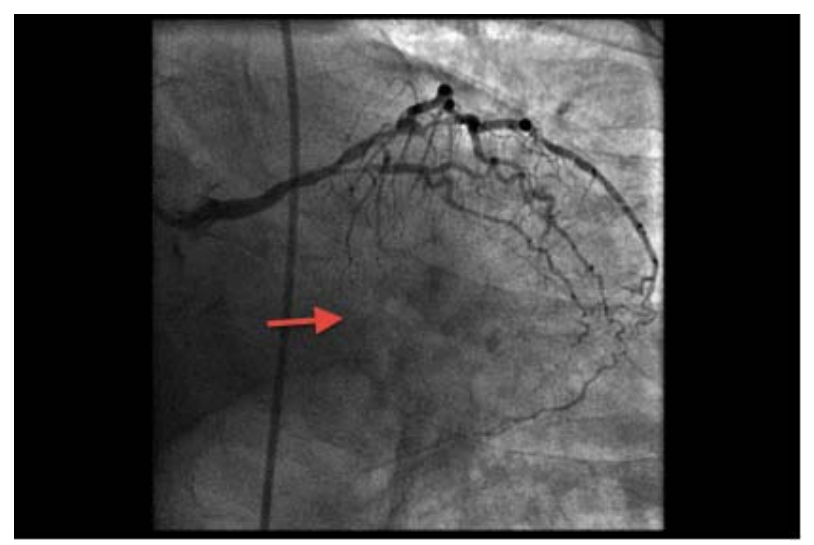

Figure 4. Sign of non-perfused myocardium. Avascular area in the posterolateral left ventricular myocardium.

cific abnormal course, traditionally called interarterial (IAC), or "between the aorta and pulmonary artery", is associated with a severe prognosis [1].

However, angiographic documentation of abnormal coronary anatomy has not led to any evidence based or consensus recommendations for functional testing and treatment. Exercise tests, intended to reproduce symptoms or to induce changes in electrocardiographic or nuclear-imaging parameters, have produced false-negative or confusing results [16].

\section{Screening}

Current guidelines, especially in those younger than age 50 years, recommend coronary CT or MRI for more accurate definition of coronary course in persons suspected of having anomalous coronary origins $[17,18]$.

\section{Relation of CAAs to Coronary Artery Disease}

There is ongoing debate among researchers as to whether CAAs predispose relevant coronary arteries to atherosclerosis. Most authors agree that there is no definitive evidence that patients with CAAs have a higher risk of developing ischaemic heart disease [6-8,19]. Garg et al. reported incidence of $28 \%$ of atherosclerotic involvement of anomalous left Cx artery [8]. Topaz et al. found coronary atherosclerosis of the anomalous arteries in $28 \%$ of patients, while the overall incidence of the disease in their series was $65 \%$. They concluded that, anomalous coronary arteries do not appear to be associated with an increased risk for development of coronary atherosclerosis [6]. In one of the largest to date review series, Wilkins et al found that $71 \%$ of patients with anomalous circumflex artery had significant coronary atherosclerosis in the proximal portion of the anomalous vessel. They postulated that the posterior course of the anomalous vessel may predispose it to atherosclerosis. The overall incidence of coronary atherosclerotic disease was $68 \%$ (64 of 94 patients) in their cohort [7]. Rigatelli et al. reviewed 15,000 coronary angiograms and concluded that CAAs did not appear to be an accelerating factor for coronary atherosclerosis in otherwise low risk patients [19].

\section{Treatment}

Symptomatic carriers of ACAOS have three management options: Observation, percutaneous intervention with stent and surgical repair.

Surgical correction, which is especially recommended for left-ACAOS that involves a large territory at risk, may consist of 1) direct re-implantation of the ectopic artery at the aortic root (a technically difficult approach); 2) un-roofing of the intramural coronary segment, from the ostium to the exit point, off the aortic wall; or 3) osteoplasty, which creates a new ostium at the end of the ectopic artery's intramural segment [20].

Two large published series of surgical experience in coronary anomalies contain only a few ACAOS cases, and even fewer have an IAC [21,22].

In the largest reported cohort of adult patients with ACAOS coming from a single institution's database collected over a 40-year period, survival was similar regardless of whether medical or surgical therapy was employed. Furthermore no appreciable improvement in long-term survival was seen in patients with ACAOS and IAC after a surgical intervention [23].

Current guidelines from American Heart Association (2008) state that "surgical repair is indicated when the left coronary arteries arise from the opposite sinus and course between the aorta and pulmonary artery. Surgical repair is also indicated when the RCA arises from the opposite sinus or courses between the aorta and pulmonary artery in association with concomitant symptoms, or when there is evidence of otherwise unexplained inducible ischemia in these territories. When the patient has an anomalous RCA and no evidence of ischemia a conser- 
vative approach may be reasonable" [17,18].

Angiographic recognition of coronary anomalies prior to cardiac surgery is of great importance. Surgical problems may follow if an anomalous vessel is excluded from perfusion during cardiopulmonary bypass or if the surgeon inadvertently incises the anomalous vessel. During valve replacement surgery, the ostium of the anomalous vessel can be obstructed or the anomalous vessel may be compressed along its course during implantation of a prosthetic aortic valve [8].

\section{Conclusions}

We have presented a rarely seen anomaly of the $\mathrm{Cx}$ artery originating from the proximal RCA. The aberrant vessel had significant atherosclerotic disease. CABG was performed to re-vascularise the $\mathrm{Cx}$ along with relevant affected left-sided vessels. Patient made an uneventful recovery.

Wide variability exists in reporting of incidence of CAAs. Limited evidence and ongoing controversy in relation to their clinical relevance and appropriate management strategies makes CAAs a challenge for cardiologists and cardiothoracic surgeons.

\section{REFERENCES}

[1] P. Angelini, "Coronary Artery Anomalies: An Entity in Search of an Identity," Circulation, Vol. 115, No. 10, 2007, pp. 1296-1305.

[2] A. Dodge-Khatami, C. Mavroudis and C. L. Backer, “Congenital Heart Surgery Nomenclature and Database Project: Anomalies of the Coronary Arteries," The Annals of Thoracic Surgery, Vol. 69, No. 3, 2000, pp. 270-297. doi:10.1016/S0003-4975(99)01248-5

[3] R. W. Alexander and G. C. Griffith, "Anomalies of the Coronary Arteries and Their Clinical Significance,” Circulation, Vol. 14, No. 5, 1956, pp. 800-805. doi:10.1161/01.CIR.14.5.800

[4] P. Angelini, "Coronary Artery Anomalies: A Comprehensive Approach," Lippincott Williams \& Wilkins, Philadelphia, 1999.

[5] O. Yamanaka and R. E. Hobbs, "Coronary Artery Anomalies in 126,595 Patients Undergoing Coronary Arteriography," Catheterization and Cardiovascular Diagnosis, Vol. 21, No. 1, 1990, pp. 28-40. doi:10.1002/ccd.1810210110

[6] O. Topaz, E. J. De Marchena, E. Perin, L. S. Sommer, S. M. Mallon and R. A. Chahine, "Anomalous Coronary Arteries: Angiographic Findings in 80 Patients," International Journal of Cardiology, Vol. 34, No. 2, 1992, pp. 129-138. doi:10.1016/0167-5273(92)90148-V

[7] C. E. Wilkins, B. Betancourt, V. S. Mathur, A. Massumi, C. M. De Castro, E. Garcia and R. J. Hall, "Coronary Artery Anomalies: A Review of More than 10,000 Patients from the Clayton Cardiovascular Laboratories," Texas Heart Institute Journal, Vol. 15, No. 3, 1988, pp. 166-173.

[8] N. Garg, S. Tewari, A. Kapoor, D. K. Gupta and N. Sinha,
"Primary Congenital Anomalies of the Coronary Arteries: A Coronary Arteriographic Study,” International Journal of Cardiology, Vol. 74, No. 1, 2000, pp. 39-46. doi:10.1016/S0167-5273(00)00243-6

[9] A. Yildiz, B. Okcun, T. Peker, C. Arslan, A. Olcay and M. B. Vatan, "Prevalence of Coronary Artery Anomalies in 12,457 Adult Patients Who Underwent Coronary Angiography," Clinical Cardiology, Vol. 33, No. 12, 2010, pp. E60-E64. doi:10.1002/clc.20588

[10] W. Antopol and M. A. Kucel, "Anomalous Origin of the Left Circumflex Coronary Artery,” American Heart Journal, Vol. 8, No. 6, 1933, pp. 802-806. doi:10.1016/S0002-8703(33)90141-6

[11] H. L. Page Jr., H. J. Engel, W. B. Campbell and C. S. Thomas Jr., “Anomalous Origin of the Left Circumflex Coronary Artery. Recognition, Angiographic Demonstration and Clinical Significance," Circulation, Vol. 50, No. 4, 1974, pp. 768-773. doi:10.1161/01.CIR.50.4.768

[12] R. R. Liberthson, "Sudden Death from Cardiac Causes in Children and Young Adults," New England Journal of Medicine, Vol. 334, No. 16, 1996, pp. 1039-1044. doi:10.1056/NEJM199604183341607

[13] B. J. Maron, J. Shirani, L. C. Poliac, R. Mathenge, W. C. Roberts and F. O. Mueller, "Sudden Death in Young Competitive Athletes: Clinical, Demographic, and Pathological Profiles," Journal of the American Medical Association, Vol. 276, No. 3, 1996, pp. 199-204. doi:10.1001/jama.1996.03540030033028

[14] A. J. Taylor, J. P. Byers, M. D. Cheitlin and R. Virmani, "Anomalous Right or Left Coronary Artery from the Contralateral Coronary Sinus: 'High-Risk' Abnormalities in the Initial Coronary Artery Course and Heterogeneous Clinical Outcomes,” American Heart Journal, Vol. 133, No. 4, 1997, pp. 428-435. doi:10.1016/S0002-8703(97)70184-4

[15] R. E. Eckart, S. L. Scoville, C. L. Campbell, E. A. Shry, K. C. Stajduhar, R. N. Potter, L. A. Pearse and R. Virmani, "Sudden Death in Young Adults: A 25-Year Review of Autopsies in Military Recruits," Annals of Internal Medicine, Vol. 141, No. 11, 2004, pp. 829-834.

[16] P. Angelini, “Coronary Artery Anomalies-Current Clinical Issues Definitions, Classification, Incidence, Clinical Relevance, and Treatment Guidelines,” Texas Heart Institution Journal, Vol. 29, No. 4, 2002, pp. 271-278.

[17] C. A. Warnes, R. G. Williams, T. M. Bashore, et al., "ACC/AHA 2008 Guidelines for the Management of Adults with Congenital Heart Disease: A Report of the American College of Cardiology/American Heart Association Task Force on Practice Guidelines," Circulation, Vol. 118, No. 23, 2008, pp. e714-e833. doi:10.1161/CIRCULATIONAHA.108.190690

[18] H. Baumgartner, P. Bonhoeffer, N. De Groot, et al., "ESC Guidelines for the Management of Grown-Up Congenital Heart Disease (New Version 2010): The Task Force on the Management of Grown-Up Congenital Heart Disease of the European Society of Cardiology,” European Heart Journal, Vol. 31, No. 23, 2010, pp. 2915-2957. doi:10.1093/eurheartj/ehq249

[19] G. Rigatelli, M. Gemelli, A. Zamboni, G. Docali, P. Rossi, 
D. Rossi, et al., "Are Coronary Artery Anomalies an Accelerating Factor for Coronary Atherosclerosis Development?” Angiology, Vol. 55, No. 1, 2004, pp. 29-35. doi:10.1177/000331970405500105

[20] P. Angelini, R. P. Walmsley, A. Libreros and D. A. Ott, "Symptomatic Anomalous Origination of Left Coronary Artery from the Opposite Sinus of Valsalva: Clinical Presentations, Diagnosis, and Surgical Repair," Texas Heart Institute Journal, Vol. 33, No. 2, 2006, pp. 171-179.

[21] E. D. Fernandes, H. Kadivar, G. L. Hallman, G. J. Reul, D. A. Ott and D. A. Cooley, "Congenital Malformations of the Coronary Arteries: The Texas Heart Institute Experience," Annals of Thoracic Surgery, Vol. 54, No. 4,
1992, pp. 732-740. doi:10.1016/0003-4975(92)91019-6

[22] R. M. Reul, D. A. Cooley, G. L. Hallman and G. J. Reul, "Surgical Treatment of Coronary Artery Anomalies: Report of a 37.5-Year Experience at the Texas Heart Institute,” Texas Heart Institute Journal, Vol. 29, No. 4, 2002, pp. 299-307.

[23] R. A. Krasuski, D. Magyar, S. Hart, V. Kalahasti, R. Lorber, R. Hobbs, G. Pettersson and E. Blackstone, "LongTerm Outcome and Impact of Surgery on Adults with Coronary Arteries Originating from the Opposite Coronary Cusp," Circulation, Vol. 123, No. 2, 2011, pp. 154162. doi:10.1161/CIRCULATIONAHA.109.921106 